\title{
De historia, de biografías, de validos y de validos de validos
}

\author{
María de los Ángeles PéRez SAMPER \\ Universidad de Barcelona \\ angelesperez@ub.edu
}

La biografía es historia y es literatura. La historia de la vida de una persona, una persona individual pero en su dimensión colectiva, porque ninguna persona está sola, aislada, separada de todos y de todo. La vida de personas de muy diferente condición, de escala histórica muy diversa, pues son muchas las vidas que merecen ser recordadas. El sujeto de la historia es el hombre en sociedad, en historia la perspectiva social no puede faltar, pero nunca falta en una buena biografía, la tiene siempre necesariamente. Es la vida de una persona en su contexto, en su tiempo, en sus lugares, con todos sus problemas, los particulares y los generales. Este enfoque personalizado de la historia, si está bien hecho, no resta nada a la gran marcha de la historia, al contrario la humaniza, la hace más concreta, más enraizada. La biografía, de una manera similar a la técnica de la microhistoria, no trata de casos particulares, más o menos anecdóticos, trata siempre de historia total, la verdadera historia. En la biografía el personaje actúa como nudo de la compleja red de la historia y hace posible así que a través de él se encuentren y se anuden los más variados aspectos económicos, sociales, culturales, artísticos, religiosos, científicos, todo en definitiva, abarcando desde los grandes acontecimientos a los actos cotidianos, desde lo más público a lo más privado, radicalmente íntimo. La biografía acerca, en definitiva la historia total, adonde tiempos, espacios y temas confluyen.

Es, pues, historia, y de la mejor, que encuentra en el estilo narrativo su manera más justa de expresión y comunicación, enlazando de esta manera con el regreso de la historia narrativa y manifestando su carácter de género literario, que siendo historia y por tanto voluntad de realidad, comunica con la novela, sin que nada tenga, sin embargo, que ver con el peligroso género de biografía anovelada, hoy en día, desgraciadamente de moda, pues con la historia todo el mundo se atreve. Y no me refiero a las biografías de autores clásicos como Stefan Zweig, que tiene una larga lista de biografías, entre ellas: Émile Verhaeren (1910), Balzac: La novela de una vida (1920), Romain Rolland: el hombre y su obra (1921) Fouché, el genio tenebroso (1929), María Antonieta (1932), María Estuardo (1934), Erasmo de Rotterdam (1934), Conquistador de los mares: la historia de Magallanes (1938). Ni siquiera a obras más recientes como la biografía de María Antonieta escrita por Antonia Fraser: María Antonieta: la última Reina (Barcelona, EDHASA, 2006). Antonia Fraser, sin ser exactamente una historiadora se ha documentado rigurosamente y ha logrado 
una interesante biografía, como también ha hecho con las seis esposas de Enrique VIII y con María Estuardo. Me refiero a esas otras obras que hoy lamentablemente proliferan y que ni son biografía ni son novela, pero que tienen pretensiones de lo uno y de lo otro.

Después de años de olvido y menosprecio, el género biográfico está experimentando actualmente un interesante renacimiento en la historiografía española. En otros países, como Gran Bretaña y Francia, la biografía siempre se mantuvo vigente, al margen de corrientes historiográficas de mayor o menor éxito y continúa hoy en auge. En Francia existen biografías clásicas. Incluso uno de los padres fundadores de la Escuela de Annales, a la que tanto debe la historiografía del siglo XX, demostró el lugar que puede y debe ocupar la biografía en la historia, me refiero a Lucien Fevbre y a su obra Un Destin. Martin Luther París, PUF, 1928. Traducción Martín Lutero México, FCE, 1975. Y la tradición continuó viva a medida que avanzaba el siglo XX. Un clásico es también la biografía de François Bluche sobre el Rey Sol, Louis XIV Paris, Fayard, 1986, que es la historia de un gran rey y la historia de Francia durante su reinado.

Una interesante reflexión sobre la biografía la hizo el historiador medievalista Jacques Le Goff a fines de los años ochenta: "¿Comment écrire une biographie historique aujourd'hui?" en Le Debat, no 54 (marzo-abril 1989), ps. 48-53. Y no sólo reflexionó, también escribió biografías. Representante destacado de la Nueva Historia, Jacques Le Goff publicó en el año 1996 una biografía sobre una de las figuras más populares de la historia de Francia, Luis IX, el único rey francés que ha sido canonizado: Saint Louis Paris, Gallimard, 1996. Esta biografía, conjuga perfectamente el relato con el análisis, la historia colectiva con la vida de un hombre. Le Goff intentó encontrar, más allá de la leyenda, el "auténtico rostro" del individuo, reconstituyendo asimismo lo esencial de su época.

Como declaró en una entrevista publicada en la revista electrónica Label-France $\left(\mathrm{n}^{\mathrm{o}} 24\right.$, junio de 1996) decidirse por la biografía constituyó un reto. Contra la idea generalizada de que a los historiadores de la Escuela de Annales no les gustaba el género biográfico, pensó que sería interesante intentarlo. Optó por el siglo XIII donde, en su opinión, destacaban tres personalidades, no sólo por su importancia, sino sobre todo por las fuentes disponibles sobre ellos: san Francisco de Asís, el emperador germánico Federico II y san Luis. Se decidió por san Luis, porque creía que la mayoría de las numerosas biografías que le habían dedicado no respondían a las exigencias del rigor histórico. Fiel al concepto de la "historia-problema" de la Escuela de Annales, su primera dificultad consistió en plantear una perspectiva que le permitiera comprender al individuo san Luis en interacción con la sociedad del siglo XIII. Especial empeño puso en evitar lo que el sociólogo Pierre Bourdieu ha denominado la "ilusión biográfica", que pretende considerar la vida de un gran hombre como un destino pre trazado, sin contar con los azares de la vida. Se dedicó, por el contrario, a mostrar las dudas, las incertidumbres, las decisiones y los momentos clave de la vida de Luis IX. Pues si bien es verdad que el hombre construye su vida, también es cierto que ésta lo construye a él. El resultado fue una gran biografía, erudita y apasionante. 
Más importante es todavía la tradición británica, que nunca olvidó el género biográfico y que ha dado continuadamente magníficas obras. Por citar sólo dos, muy relacionadas con España, la breve, pero lograda, biografía de Geoffrey Parker sobre Felipe II, Philip II, (Boston and London, 1978, traducida al español (Madrid, Alianza Editorial, 1997) y recientemente ampliada y publicada en español con el título ambicioso de Felipe II: La biografía definitiva Barcelona, Editorial Planeta, S.A. 2010. Y por encima de todo la monumental biografía de John H. Elliott sobre el Conde Duque: The count-duke of Olivares London \& New Haven, 1986, traducida con el título: El conde duque de Olivares. El politico en una época de decadencia Barcelona, Crítica, 1990.

Preguntado Elliott en una entrevista sobre la falta de biografías en la historiografía española, frente a la rica tradición anglosajona, su respuesta resulta muy reveladora. En Inglaterra la biografía se considera una forma valiosa de historia, especialmente la biografía política: "En cuanto a la ausencia de biografías, creo que no es un defecto español; es más bien algo que tienen los ingleses y tal vez los estadounidenses: ese interés biográfico, que no sé de dónde viene, ha dado una gran tradición de biografías políticas, especialmente en mi país, de hombres de Estado. Se considera una forma valiosa de historia. Cuando se investigan los problemas de una sociedad siguiendo la perspectiva específica de algún político que haya sido responsable de solucionarlos, se obtiene al mismo tiempo una idea de los problemas y de las resistencias a las soluciones. Eso es muy interesante, porque uno sabe que, al observar desde un punto de vista particular, la perspectiva siempre será parcial; sin embargo, al mismo tiempo, piense usted en cuántos documentos importantes pasan por la mesa de un hombre de Estado que está enterado de tantas cosas, y esos documentos quedan, de modo que uno puede ver lo que ha sido importante para la gente de esa generación. Considere, por ejemplo, aquella "reputación" de los hidalgos españoles, que aparece tantas veces en los documentos del siglo diecisiete: ahí se da uno cuenta de la importancia que tiene en el enfoque que se eligió para solucionar los problemas. (Letras Libres, septiembre de 2003, "El desengaño del Imperio Español: Entrevista con John Elliott", por Enrique Krauze).

En España la biografía no sólo es escasa, sino que fue denostada en los años sesenta y setenta como un género indigno de pertenecer a la historia por muchos historiadores apegados de manera exclusiva y excluyente a las últimas tendencias historiográficas. Pero siguió habiendo grandes historiadores que la defendieron, como sucedía con Carlos Seco Serrano, entonces catedrático de Historia General de España en la Universidad de Barcelona, que siempre ponía a sus alumnos, como ejemplo de una buena biografía y una buena manera de hacer historia la obra de su maestro Jesús Pabón: Cambó Barcelona, Alpha, 1952-1969, 3 vols. El propio Carlos Seco es autor de muy buenas biografías de Alfonso XIII Arlanza Ediciones, 2001) y Alfonso XII Barcelona, Editorial Ariel, 2007. Preconiza biografías desde cerca. Seco, lejos de arredrarse ante la seducción que con frecuencia ejerce el personaje sobre el biógrafo, tanto en el momento de la elección como en el transcurso de la obra, defiende siempre, y especialmente en la biografía, como valor máximo del historiador la capacidad de comprensión. 
En época más reciente la vigencia de la biografía ha sido demostrada por importantes historiadores mediante las obras que han realizado. Basten algunos ejemplos destacados. Luis Suárez Fernández ha escrito biografías fundamentales sobre los Reyes Católicos: Isabel I, Reina Barcelona, Ariel, 2002 y Fernando el Católico Barcelona, Ariel, 2004. María Victoria López-Cordón Cortezo, haciendo interactuar al personaje con su tiempo, sobre el telón de fondo del siglo de la razón y de las luces, ha logrado una sugestiva evocación de una figura femenina relativamente poco conocida, pero no por ello menos interesante: Condición femenina y razón ilustrada: Josefa Amar y Borbón Zaragoza, Prensas Universitarias de Zaragoza, 2005.

De auténtico fenómeno editorial, por su capacidad de conectar con el gran público, cabe calificar la obra prolífica de Manuel Fernández Álvarez, historiador que prestó especial atención y dedicación al género biográfico a lo largo de su dilatada carrera, con una serie de obras sobre personajes muy variados: Carlos V: un hombre para Europa, Madrid, Cultura hispánica, 1976, Jovellanos, el patriota, 1988 y nueva edición Madrid, Espasa Calpe, 2001, Fray Luis de León: la poda floreciente, 15911991, Madrid, Espasa Calpe, 1991, Juana la Loca, la cautiva de Tordesillas, 1994 y nueva ed. Madrid, Espasa Calpe, 2006, Felipe II y su tiempo, Madrid, Espasa Calpe, 1998, Carlos V, el césar y el hombre, Madrid, Espasa Calpe, 1999, El príncipe rebelde, 1996, nueva ed. Madrid, Espasa Calpe, 2000, Isabel la Católica, Madrid, Espasa-Calpe, 2006, El Duque de hierro. Fernando Álvarez de Toledo, III Duque de Alba, Madrid, Espasa-Calpe 2007, llegando incluso a titular como biografía su última síntesis de Historia de España: España. Biografía de una nación, Madrid, Espasa-Calpe, 2010.

Interesante es el caso de Isabel Burdiel, que ha escrito biografía y ha pensado la biografía. Se ha atrevido con la polémica y maltratada figura de la reina Isabel II en dos libros sucesivos, primero Isabel II. No se puede reinar inocentemente Madrid, Espasa Calpe, 2004 y después Isabel II. Una biografía 1830-1904, Madrid, Taurus, 2010, completando así la larga y azarosa vida de la reina. Una sugestiva reflexión de Isabel Burdiel sobre la biografía se encuentra en "La dama de blanco. Notas sobre la biografía histórica" en Isabel Burdiel y Manuel Pérez Ledesma (coords.): Liberales, agitadores y conspiradores. Biografías heterodoxas del siglo XIX (Madrid, EspasaCalpe, 2000, pp. 17-48.) Muy aconsejable el libro de J.C. Davis e Isabel Burdiel (eds.): El otro, el mismo. Biografía y autobiografía en Europa (siglos XVII-XX), Valencia, Publicacions de la Universitat de València, 2005.

Y no se trata sólo de grandes maestros e historiadores consagrados. Especialmente prometedor es el amplio panorama de jóvenes historiadores que están dedicando su tesis doctoral a biografiar a los más variados personajes. Especial mención merece la obra de la doctora Ana Morte Acín, presentada como tesis doctoral en la Universidad de Zaragoza, el año 2008, luego convertida en libro, una biografía dedicada a la discutida y sugerente figura de sor María de Jesús de Ágreda, que acaba de publicarse recientemente con el título Misticismo y conspiración. Sor María de Ágreda en el reinado de Felipe IV, Zaragoza, Institución Fernando el Católico, 2010. Las numerosas tesis en curso de tema biográfico aseguran un buen futuro para este género historiográfico. 
La relevancia de la biografía queda también de manifiesto en la magnífica iniciativa que la Real Academia de la Historia ha emprendido a fines del siglo XX, la elaboración de un Diccionario Biográfico Español. El 21 de julio de 1999 la Real Academia de la Historia firmó un convenio con el Ministerio de Educación, Cultura y Deporte con objeto de formar el Diccionario, en un plazo de ocho años. Para fijar los criterios de colaboración de las academias iberoamericanas de la Historia, en los días 8 y 9 de junio del año 2000 se celebraron en Madrid las Jornadas del Diccionario biográfico. Participaron los presidentes y directores de las distintas academias, españolas e iberoamericanas, y todos los colaboradores académicos, numerarios y correspondientes. Para mantener vivo el proyecto cara al futuro se ha creado un Centro de Estudios Biográficos en la Real Academia de la Historia que actualiza y completa periódicamente una importante base de datos.

En este panorama tan propicio a la valoración de la biografía se enmarcan los dos libros que se comentan, el de Alfredo Alvar Ezquerra, El Duque de Lerma. Corrupción y desmoralización en la España del siglo XVII, Madrid, La Esfera de los Libros, 2010 y el de Santiago Martínez Hernández: La sombra del valido. Privanza, favor y corrupción en la corte de Felipe III, Madrid, Centro de Estudios Europa Hispánica y Marcial Pons Historia, 2009.

Si la biografía quedó largos años olvidada en la historiografía española, algo similar sucedió con el reinado de Felipe III. Aunque existían algunas aportaciones valiosas de los años cincuenta, como los estudios de Carlos Seco Serrano «Asti. Un jalón en la decadencia española». Arbor, t. XXVIII, no 107 (nov. 1954), pp. 277-291 y "Los comienzos de la privanza de Lerma según los embajadores florentinos" en Boletín de la Real Academia de la Historia, CXLIV (enero-marzo 1959), pp. 75-101, no será hasta medio siglo más tarde cuando el tema volverá a ocupar un puesto importante en la historiografía. En los últimos años, el reinado de Felipe III ha experimentado un gran florecimiento historiográfico. Notable es la obra de Antonio Feros sobre el gobierno de corte, con numerosos artículos publicados como "El viejo monarca y los nuevos favoritos: los discursos sobre la privanza en el reinado de Felipe III," Studia Historica, 17, pp. 11-36. "Almas gemelas: monarcas y favoritos en la primera mitad del siglo XVII," España, Europa y el mundo atlántico, Madrid, Marcial Pons Ediciones, 2001. "Valimiento y la construcción de nuevos paradigmas políticos," José A. Escudero (ed.): Los Validos, Madrid, Servicio de Publicaciones Universidad Rey Juan Carlos - Ed. Dykinson, 2005. Y una biografía del gran valido de Felipe III: Kingship and Favoritism in the Spain of Philip III, 1598-1621, (Cambridge University Press, 2000), obra traducida, revisada y aumentada: El Duque de Lerma. Realeza y privanza en la España de Felipe III (Madrid, Marcial Pons, 2002).

Importantísima la contribución al tema de Patrick Williams, culminada con su magnífica biografía del valido: The great favourite. The Duke of Lerma and the court and government of Philip III of Spain, 1598-1621, Manchester-Nueva York, Manchester University Press, 2006, traducida al español: El gran valido. El Duque de Lerma. La corte y el gobierno de Felipe III 1598-1621, Valladolid, Junta de Castilla y León, 2010, una de esas biografías que honran el género. 
A estos estudios se ha sumado la gran obra de José Martínez Millán y María Antonietta Visceglia (dirs.): La Monarquía de Felipe III, 4 vols. Vols. I y II: La Casa del Rey, Vol. III: La Corte, Vol. IV: Los Reinos, Madrid, MAPFRE, 2005-2008. Obra fundamental, por todo lo que aporta y por todo lo que ofrece para posteriores obras.

Validos y validos de validos. Lerma y Rodrigo Calderón, la sombra del rey y la sombra del valido. Un reinado de sombras, más que de personajes, donde una sombra proyectaba a su vez otra sombra, creando un complejo entramado de razones e intereses. El valimiento es una gran cuestión historiográfica, capital para la historia política del siglo XVII. Existen importantes reflexiones generales, algunas escritas hace ya muchos años, como la aproximación de Francisco Tomás y Valiente: Los validos en la monarquía española del siglo XVII (estudio institucional), Madrid, Instituto de Estudios Políticos, 1963, otras recientes, como el destacado libro de José A. Escudero (ed.): Los Validos, Madrid, Servicio de Publicaciones Universidad Rey Juan Carlos - Ed. Dykinson, 2005. Y existen obras capitales sobre el valido por excelencia, Olivares, la biografía de Elliott por encima de todas. Pero añadir la figura de Lerma y de sus criaturas proporciona un panorama mucho más rico, por muchas razones, entre las que no es la menor, ser el Duque de Lerma el primero de los grandes validos del siglo XVII español.

Corrupción de corrupciones y todo corrupción. Junto con el valimiento, la corrupción es la otra gran cuestión, tal como indican ya los subtítulos de ambos libros que comentamos, "corrupción y desmoralización" en el de Alvar Ezquerra, "privanza, favor y corrupción” en el de Martínez Hernández. Efectivamente, una corrupción que todo lo contaminaba, que se extendía como una mancha de aceite, cada vez mayor, hasta alcanzar todo o casi todo, pues sólo en esa ampliación permanente de complicidades se mantiene un sistema de corrupción en el reinado de Felipe III y en cualquier otra época. Lerma, inteligente e interesado, siempre buscando a la vez el bien del monarca y de la Monarquía y el suyo propio, anteponiendo con frecuencia el suyo por encima del bien del monarca y de la Monarquía y no digamos del bien de los súbditos. Grande, pero ambicionando siempre mayor grandeza. Un reto importante que Alvar Ezquerra ha asumido con valentía. Lerma el primero y, detrás, toda una larga serie de sombras, en el poder y en la corrupción, sombras como Rodrigo Calderón, personaje y mito, que merecía un buen estudio, el que Martínez Hernández le ha dedicado. Y otras muchas sombras, unas ya abordadas, como Pedro Franqueza, estudiado por Josep Maria Torras Ribé: Poders i relacions clientelars a la Catalunya dels Austrias: Pere Franquesa (1574-1614), Vic, Eumo Editorial, 1998 y otras muchas sombras todavía por estudiar.

Alfredo Alvar tiene una gran experiencia como biógrafo. Ha estudiado personajes muy importantes de la historia de España: Isabel la Católica. Una reina vencedora, una mujer derrotada, Madrid, Temas de Hoy, 2002 y Cervantes. Genio y Libertad Madrid, Temas de Hoy, 2004. Figuras diversas en tiempos diversos, figuras gigantescas. Si de Isabel la Católica y de Cervantes existen numerosas biografías y ello no le impidió a Alvar dar su propia versión, igualmente ha sucedido con Lerma; el reciente libro de Williams no ha sido un obstáculo para ofrecer su personal perspectiva. 
En la biografía del Duque de Lerma, Alfredo Alvar da desde el comienzo las claves esenciales de su interpretación. En el prólogo habla de poder y dominación, de la legitimidad del poder, de las complejas relaciones del valido con el rey, del carisma y la enorme inteligencia del personaje, habla de cleptocracia y de corrupción, de una manera cínica de gobernar, del principal objetivo del valido que era el enriquecimiento, el suyo, el de su familia, un Lerma contradictorio, codicioso y también dadivoso, amante de las artes, por sí mismas y como instrumento de poder, gran mecenas y gran coleccionista, hombre inquieto, insatisfecho, consciente de sus paradojas y absurdos, que ni vivía en paz, ni dejaba vivir en paz, a pesar de preconizar una política de prudente pacifismo. Alfredo Alvar ha estudiado a Lerma a fondo, desde múltiples perspectivas, y, sin embargo, confiesa no entenderlo: "He querido ser generoso con las formas de obrar de Lerma. Pero no le he podido entender".

Declara haber hecho su biografía desde la historia y desde la historiografía: "Para mí, el ejercicio de historiador es doble, tanto el de aproximarse al pasado, cuanto el de exégeta de lo escrito. Tan importante es la Historia, como la historiografía." Afirma que escribe para aprender, se manifiesta deudor de todos los que han estudiado antes aquel tiempo y aquellos personajes y declara como fuente esencial la reconstrucción del archivo personal de Lerma, con consultas a numerosos archivos y bibliotecas.

El libro está organizado en nueve capítulos. El primero es de caràcter introductorio, reflexionando sobre la posibilidad de formas estructurales de cleptocracia. El segundo trata sobre la familia. El tercero está dedicado al apogeo del poder, el ejercicio de la política interior, a través del nepotismo. El cuarto se refiere a la política exterior. A partir del capítulo quinto se abordan las sucesivas crisis, primero se aborda el problema del pacifismo claudicante y la cleptocracia. En el capítulo sexto se estudia el triunfo del confesonario real como poder rival. El capítulo séptimo analiza a Lerma ante el abismo de la pérdida del poder. El octavo se consagra al vacío ante el final, en el que sólo las artes le acompañarían. El capítulo noveno, a manera de colofón. Se añaden al final apéndices, notas y bibliografía. En total 664 páginas que desarrollan la vida de don Francisco Gómez de Sandoval y Rojas, duque de Lerma, personaje principal, acompañado siempre por la figura del rey Felipe III, rodeado de infinidad de otros personajes, de muy variada condición, y en el fondo los millones de súbditos de la Monarquía Española y millones de gentes de Europa y América, como no podía ser menos en un tiempo en que España continuaba siendo la potencia hegemónica. Un tiempo y un mundo en que los síntomas alarmantes de declinación se anunciaban, a pesar del esplendor cultural.

Trabajo serio, pleno de rigor científico, pero sin caer en el "rigor mortis", como dice con humor Alvar en su prólogo. Porque lo riguroso no está necesariamente reñido con lo ameno. Y si la historia no tiene que ser aburrida, la biografía mucho menos, porque la vida es siempre apasionante, mucho más la de un personaje como el Duque de Lerma.

Lerma no estaba solo. Su mundo estaba poblado de sus criaturas. En segundo plano, pero figura emblemàtica es la de Rodrigo Calderón, biografiada por Santiago Martínez. Con gran justicia afirma Patrick Williams en su prólogo que don Rodrigo ha encontrado a su historiador y ese historiador es Santiago Martínez. Buen conocedor 
de la época y de la corte de Felipe III, el autor llevaba ya unos años ocupándose del personaje. Como él mismo revela, el libro "es el resultado de un atractivo proyecto, alentado desde su concepción en 2005 por el profesor José Manuel Calderón Ortega". El sugestivo perfil del personaje ha suscitado recientemente otros estudios, como la tesis doctoral de Karidjatou Diallo: "La figura de Don Rodrigo Calderón a través de la literatura (siglos XVII-XXI)", bajo la dirección de la doctora Isabel Colón Calderón, presentada en la Facultad de Filología de la Universidad Complutense de Madrid el año 2009.

Comienza Santiago Martínez su libro con el relato de la muerte de su personaje. Es un gran acierto. Si algo conocemos todos o casi todos de Rodrigo Calderón es su muerte, una "muerte inmortal" como diría el Conde de Villamediana. También Quevedo, con su certera pluma, lo expresó magistralmente: "La muerte de don Rodrigo Calderón fue lo que vivió y su vida no fue más que su muerte". En efecto, la vida de Rodrigo Calderón es su muerte. Explicar su muerte es explicar su vida. Explicar su vida es explicar su muerte. Muerte es, pues, la primera clave, orgullo es la segunda. "Tener más orgullo que don Rodrigo en la horca" es la expresión por excelencia en lengua española de orgullo desmesurado. Si el orgullo era categoría en la España de aquellos tiempos, el orgullo de don Rodrigo fue su quintaesencia en la vida y en la muerte. Pecado capital, el orgullo fue tal vez, más todavía que la misma corrupción de la que fue acusado, la causa de su perdición.

La obra, de 398 páginas, está estructurada en cinco capítulos. El primero está dedicado a la génesis del favorito. El segundo se refiere a la próspera fortuna y a la cumbre del poder. El tercero al retiro y la caída. El cuarto al ocaso, arresto y cautiverio. El quinto al oprobio y al olvido. En definitiva, meteórico encumbramiento, que no hace sino subrayar el precipicio por el que se despeña acto seguido don Rodrigo, como si fuera arrastrado por el destino insuperable del protagonista de una tragedia, sacrificado por el propio sistema que había contribuido a crear y del que tanto se había antes beneficiado. Culpable, sin duda, pero utilizado como víctima propiciatoria para dar ejemplo, cerrando así un reinado, el de Felipe III y Lerma, y comenzando otro nuevo, el de Felipe IV y Olivares, que querían marcar meridianamente la diferencia. Completa el libro un epílogo, un sumario documental e historiográfico, una genealogía, una cronología, la referencia de fuentes, de bibliografía y de ilustraciones y el índice onomástico. Todos ellos útiles complementos.

Obra rigurosa, muy bien documentada, pero sin que la erudición le haga perder nada de vitalidad. Como escribe el profesor Williams en su prólogo: "Santiago Martínez Hernández nos ofrece, pues, una imagen de una viveza excepcional, con los tonos de un retrato de Zurbarán, resplandeciente por la intensidad -y los contrastesde sus colores, por la consistencia de su hondura psicológica y, sobre todo, por su misma humanidad."

Dos biografías, dos libros de historia, historia de verdad, de la mejor, con toda la pasión y el suspense de una buena novela. Porque la biografía es historia y es literatura. Leer los dos libros ayuda a comprender mejor el uno y el otro, y los dos nos ayudan, en definitiva, a comprender mejor lo comprensible y lo incomprensible de aquel mundo, la España de Felipe III, y de aquel tiempo, las primeras décadas del 
siglo XVII, porque en la historia la clave son los seres humanos que la hacemos y la deshacemos, los que la vivimos y los que la recordamos, personas como el duque de Lerma y como Rodrigo Calderón, protagonistas de estos dos libros, personas como Alfredo Alvar y como Santiago Martínez, los dos historiadores que los han escrito y a través de ellos han puesto en comunicación el pasado y el presente, personas como todos nosotros sus afortunados lectores. Entre personas anda el juego. Eso es la biografía y eso es la historia, nada más y nada menos. 